\title{
Implementasi Framework Laravel pada Sistem Informasi Penyewaan Kamera (Studi Kasus Di Rumah Kamera Semarang)
}

\author{
Devi Purnama Sari ${ }^{1^{*}}$, Rony Wijanarko ${ }^{2}$ \\ ${ }^{1,2}$ Jurusan Teknik Informatika, Fakultas Teknik, Universitas Wahid Hasyim \\ Jl. Menoreh Tengah X/22, Sampangan, Semarang 50236. \\ "Email: devi.purnamasari450@gmail.com
}

\begin{abstract}
Abstrak
Penyewaan kamera merupakan sebuah usaha penyewaan yang menyediakan pelayanan jasa penyewaan kamera. Proses bisnis di tempat penyewaan kamera pada umumnya masih mengharuskan pelanggan untuk datang dalam melakukan penyewaan dan mengatur jadwal penyewaan yang diinginkan. Tempat usaha penyewaan kamera di Rumah Kamera Semarang, proses pengelolaan penyewaan kameranya masih dilakukan secara konvensional. Implementasi framework laravel pada sistem informasi penyewaan kamera di rumah kamera semarang yang berbasis web, dapat digunakan untuk memudahkan pelanggan dalam melakukan pemesanan dan melihat jadwal pemesanan kamera serta memudahkan petugas dalam mengelola data. Dengan adanya sistem ini, pelanggan bisa melakukan pemesanan secara online dengan memanfaatkan jaringan internet yang berkembang saat ini yang begitu pesat. Sistem ini dibangun menggunakan metode waterfall dengan framework PHP yaitu Laravel versi 5.7 didukung dengan database MySQL untuk mengolah basis datanya.
\end{abstract}

Kata kunci: Framework, Laravel, Penyewaan, Sistem Informasi

\section{PENDAHULUAN}

Perkembangan sistem informasi dengan menggunakan komputer merupakan sebuah media yang dapat memudahkan seseorang dalam mengelola data dengan tujuan untuk mendapatkan informasi dengan mudah agar bisa diakses oleh siapa saja, kapan saja, serta akurat dalam mendapatkan informasi tersebut. Pengelolaan data dan informasi yang baik sangat penting untuk kebutuhan suatu organisasi, lembaga apalagi yang berhubungan bisnis. Salah satu contohnya yaitu sistem penyewaan kamera.

Penyewaan kamera merupakan sebuah usaha penyewaan yang menyediakan pelayanan jasa penyewaan kamera. Proses bisnis di tempat penyewaan kamera pada umumnya masih mengharuskan pelanggan untuk datang dalam melakukan penyewaan dan mengatur jadwal penyewaan yang diinginkan. Sehingga pelanggan tidak mengetahui jadwal yang masih kosong secara langsung.

Tempat usaha penyewaan kamera di Rumah Kamera Semarang, proses pengelolaan penyewaan kameranya masih dilakukan secara konvensional. Untuk itu pentingnya dibuatkan sistem ini agar para pelanggan yang ingin booking kamera untuk mengabadikan moment bisa melihat dari status kamera yang sudah di booking dan yang belum dibooking agar terhindar dari kesalahpahaman yang bisa membuat pelanggan merasa kecewa karena adanya pelanggan memesan pada hari yang sama, sehingga jadwal hari tersebut menjadi berbenturan dikarenakan ketidaktahuan yang sudah memesan kamera. Selanjutnya agar bisa terhindar dari jadwal hari yang sudah dipesan pelanggan untuk bisa diketahui pelanggan yang lain dengan menggunakan sistem informasi penjadwal penyewaan kamera yang berbasis web, serta memudahkan pengelola penyewaan kamera dalam mengelola laporan penyewaan kamera .

Berdasarkan uraian dari latar belakang masalah tersebut maka penulis mengangkat sebuah penelitian dengan judul " Implementasi Framework Laravel Pada Sistem Informasi Penyewaan Kamera (Studi Kasus Di Rumah Kamera Semarang)" .

\section{TINJAUAN PUSTAKA \\ 2.1 Framework}

Framework adalah komponen pemrograman yang siap re-use (bisa digunakan ulang) kapan saja, sehingga programmer tidak harus membuat skrip yang sama untuk tugas yang sama. Misalkan programmer ingin halaman-halaman web menampilkan data dengan paginasi (paging) halaman, framework telah menyediakan fungsi paging tersebut 
sedangkan programmer cukup menggunakan fungsi tersebut pada saat coding, tetapi tentu dengan kaidah- kaidah yang ditetapkan oleh masing - masing framework (Kasman,2015)

\subsection{Laravel}

Laravel adalah sebuah framework web berbasis PHP yang open-source dan tidak berbayar, diciptakan oleh Taylor Otwell dan diperuntukkan untuk pengembangan aplikasi web yang menggunakan pola $M V C$. Struktrur pola $M V C$ pada laravel sedikit berbeda pada struktur pola $M V C$ pada umumnya. Di laravel terdapat routing yang menjembatani antara request dari user dan controller. Jadi controller tidak langsung menerima request tersebut (Yudanto dkk, 2017).

\subsection{Sistem Informasi}

Sistem informasi adalah suatu sistem yang tujuannya menghasilkan informasi. Sebagai suatu sistem, untuk dapat memahami sistem informasi, akan lebih baik jika konsep dari sistem itu dipahami terlebih dahulu. Demikian juga sebagai sistem penghasil informasi, maka konsep informasi perlu dipahami terlebih dahulu (Saputra, 2015).

\subsection{Konsep Dasar Penyewaan}

Pengertian sewa menurut kamus besar bahasa Indonesia (departemen pendidikan dan kebudayaan republik Indonesia, 2001) adalah pemakaian sesuatu dengan membayar uang sewa, uang yang dibayarkan karena memakai atau meminjamkan sesuatu, yang boleh pakai dengan membayar uang dengan uang. Sedangkan pengertian penyewaan adalah proses, cara, perbuatan menyewa atau menyewakan. Yang dimaksud dengan sewa, yaitu balas jasa atas sewa ruangan dalam keadaan kosong yang dapat ditagih di muka (pada awal penyewaan) atau di belakang, sesuai dengan perjanjian (Frayoga dan Fitriyani, 2016).

\section{METODE PENELITIAN}

\subsection{Metode Pengumpulan Data}

Metode pengumpulan data adalah sebuah metode tentang bagaimana dalam mengumpulkan data-data yang ada. Adapun metode pengumbulan data yang digunakan adalah:

1. Metode Pengamatan Langsung (Observasi)

2. Metode Wawancara (Interview)

3. Metode Kepustakaan

\subsection{Tahap Pelaksanaan}

Dalam perancangan aplikasi ini, penulis mengimplementasikan metode Waterfall atau sering disebut classic life cycle sebagai metode pengembangan perangkat lunak yang meliputi tahap berikut ini:

1. Perencanaan

2. Analisis perangkat lunak (software analysis)

3. Perancangan perangkat lunak (software design)

4. Implementasi perangkat lunak (coding)

5. Pengujian perangkat lunak (testing)

6. Pemeliharaan (maintenance)

Pemodelan sistem dilakukan dengan menggunakan metode UML yang meliputi use case diagram dan activity diagram.

\section{PERANCANGAN DAN IMPLEMENTASI 4.1 Desain Unified Modeling Language}

Dalam pemodelan sistem informasi penyewaan kamera pada Rumah Kamera Semarang ini penulis menggunakan metode UML dan terdapat tiga diagram UML yang akan digunakan sesuai dengan kebutuhan sistem, yaitu:

\section{Use Case Diagram}

Pada Gambar 1. merupakan diagram use case yang akan mempermudah dalam memahami peran dari setiap aktor dalam menggunakan sistem yang akan dibuat oleh penulis.

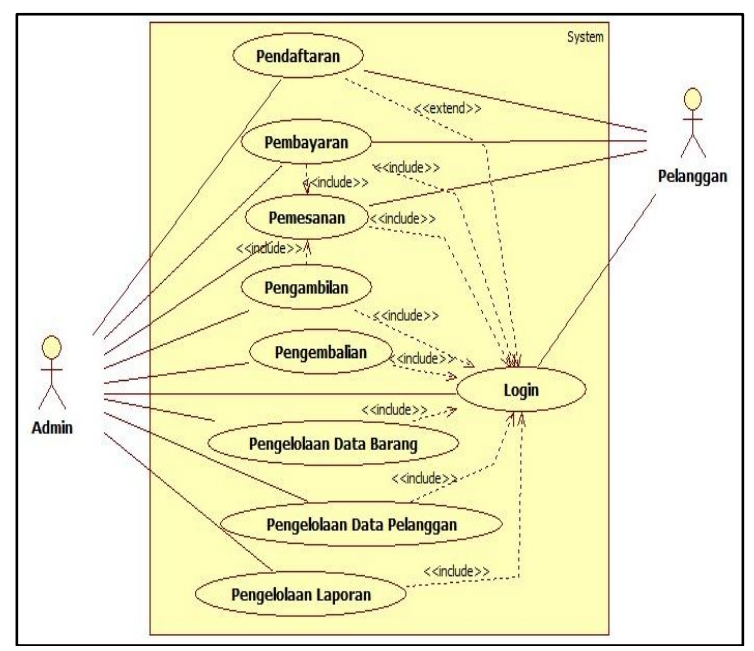

Gambar 1. Use Case Diagram

2. Activity Diagram 
Berikut ini terdapat activity diagram untuk mempermudah memahami alur kegiatan dari suatu sistem dan juga sebagai acuan dalam pembuatan setiap fungsi dalam sistem.

\section{a. Activity Diagram Pendaftaran}

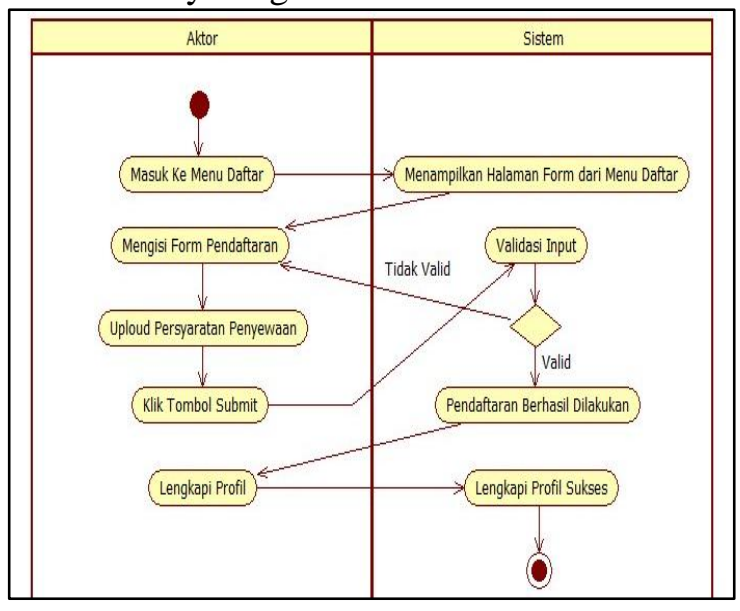

Gambar 2. Activity Diagram Pendaftaran

b. Activity Diagram Login

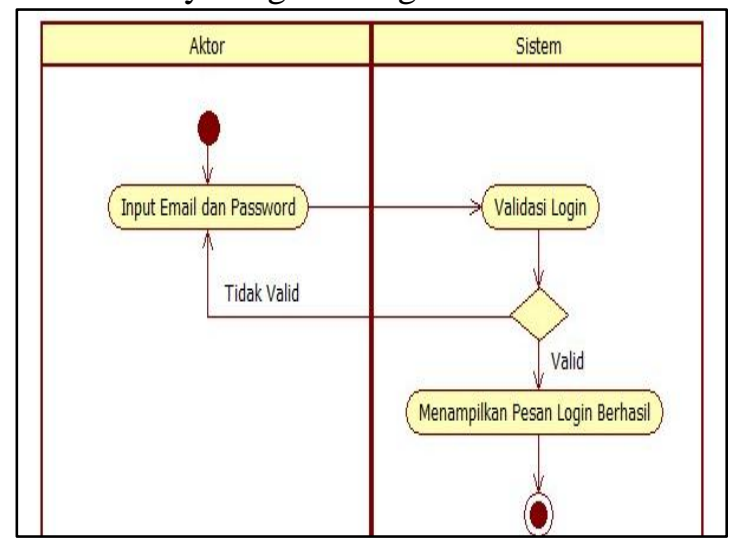

Gambar 3. Activity Diagram Login

c. Activity Diagram Pemesanan

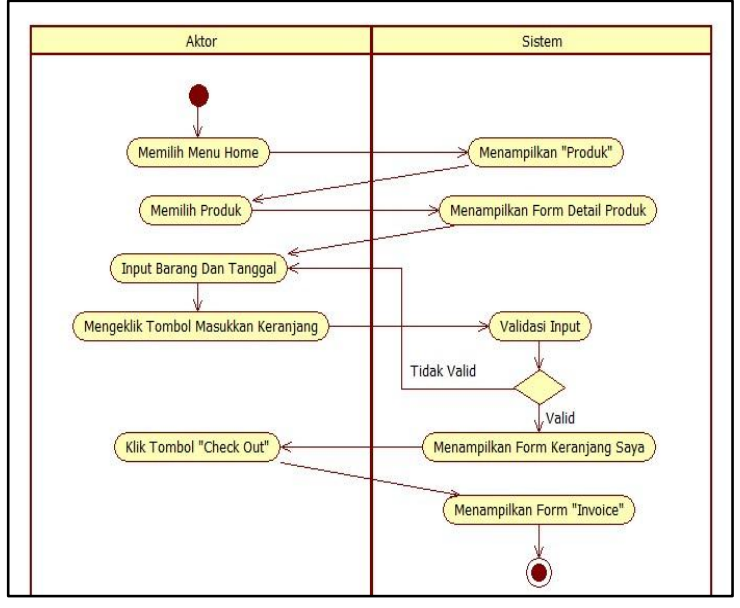

Gambar 4. Activity Diagram Penyewaan d. Activity Diagram Pembayaran

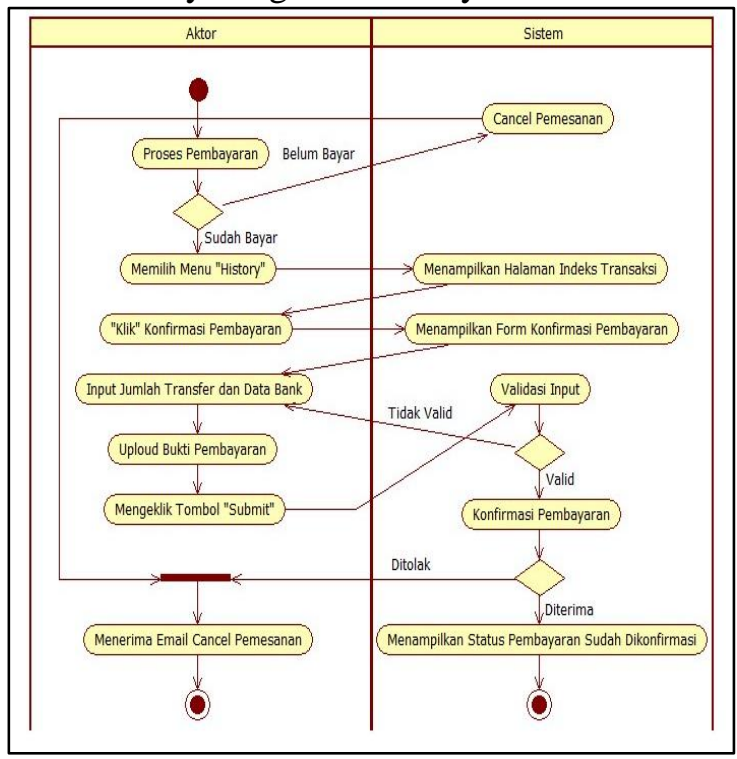

Gambar 5. Activity Diagram Pembayaran

e. Activity Diagram Pengelolaan Data Barang

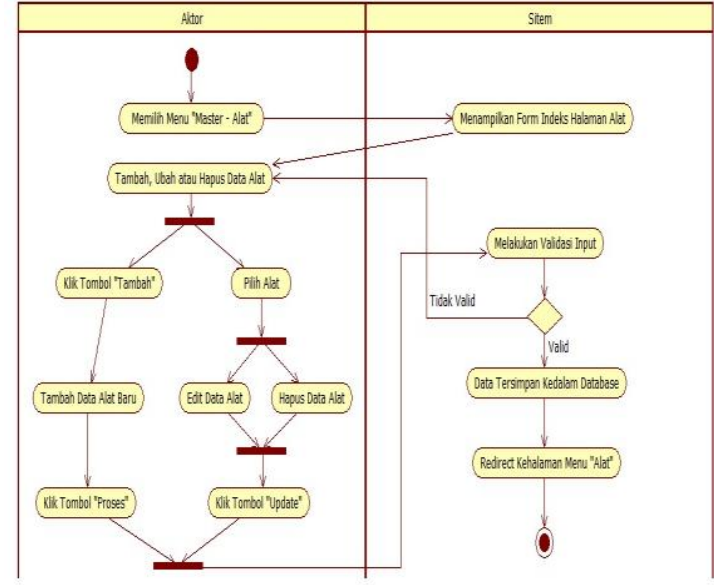

Gambar 6. Activity Diagram Pengelolaan Data Barang

f. Activity Diagram Laporan

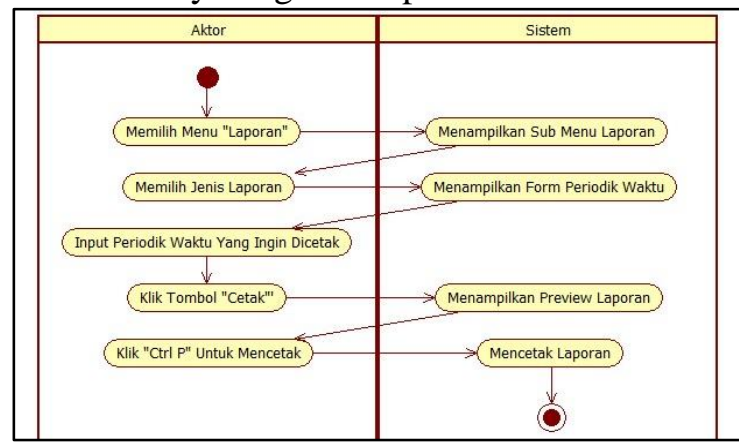

Gambar 7. Activity Diagram Pengelolaan Laporan 
g. Activity Diagram Pengelolaan Data Pelanggan

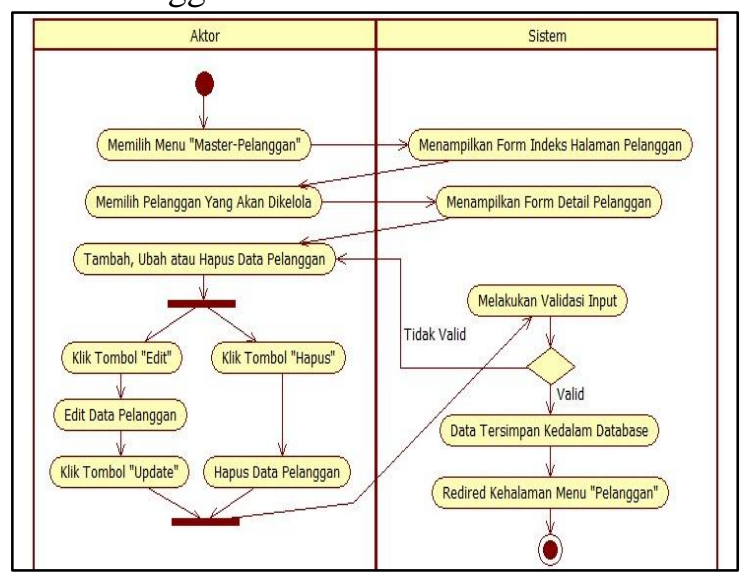

Gambar 8. Activity Diagram Pengelolaan Data Pelanggan

\subsection{Desain UI (User Interface)}

1. Halaman Beranda

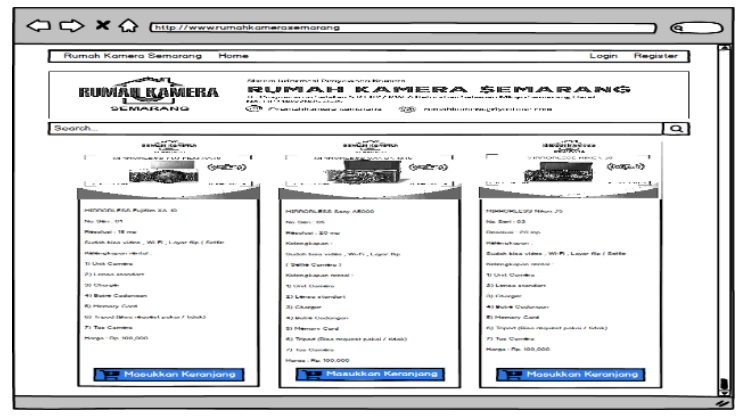

Gambar 9. Mockup Beranda

2. Halaman Login

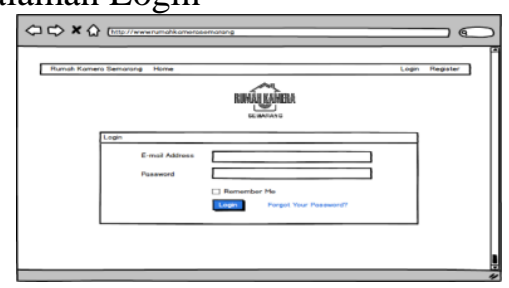

Gambar 10. Mockup Login

3. Halaman Register

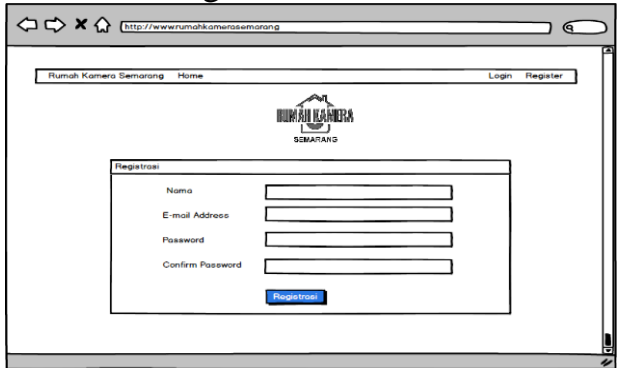

Gambar 11. Mockup Register
HASIL DAN PEMBAHASAN

5.1 Struktur Aplikasi

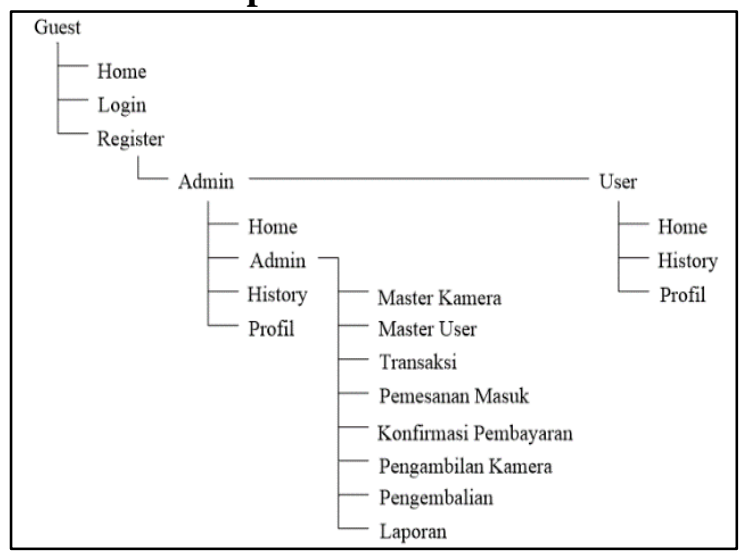

Gambar 12. Struktur Sistem

\subsection{Desain UI User}

1. Halaman Beranda

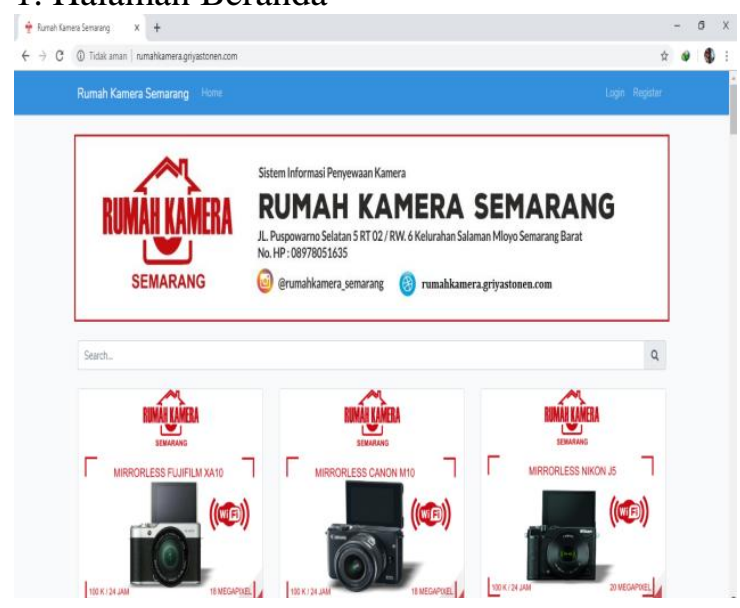

Gambar 13. Halaman Beranda

Pada Gambar 13. merupakan halaman ketika pertama kali guest mengakses sistem. Di halaman tersebut terdapat menu home untuk melihat beranda sistem, menu login untuk user yang sudah terdaftar pada sistem dan menu register untuk user yang belum terdaftar di dalam sistem.

2. Halaman Login

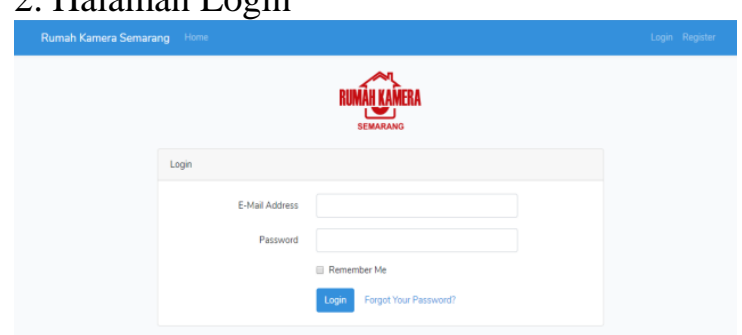

Gambar 14. Halaman Login 
Pada Gambar 14 terdapat login ketika ingin masuk ke dalam sistem langsung memasukkan E-Mail Address dan password. Jika lupa password pilih link Forgot your password.

\section{Halaman Register}

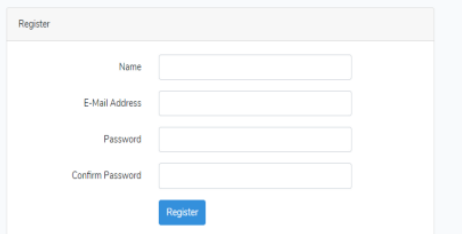

Gambar 15. Halaman Register

Pada Gambar 15. pelanggan yang ingin menjadi pengguna sistem harus melakukan pendaftaran dengan mengisi form nama, email address dan password. Jika email yang digunakan untuk register sudah terdaftar pada database sistem maka register akan berhasil dan langsung diarahkan ke halaman login, jika tidak berhasil maka akan muncul pesan error.

\subsection{Desain UI Admin}

\section{Halaman Master Kamera}

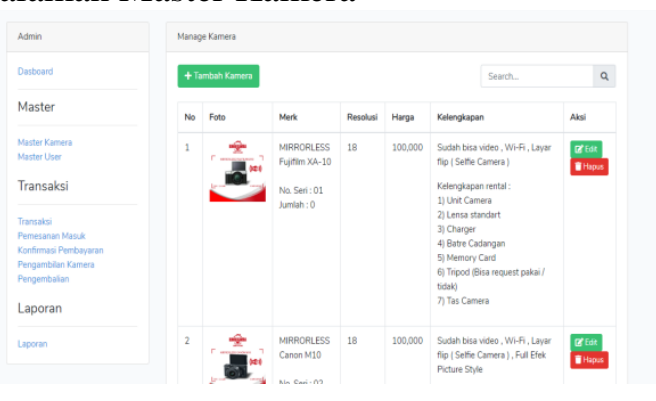

Gambar 16. Halaman Master Kamera

Halaman ini berfungsi untuk menambahkan, mengedit, melihat detail data dan menghapus data kamera.

\section{Halaman Master User}

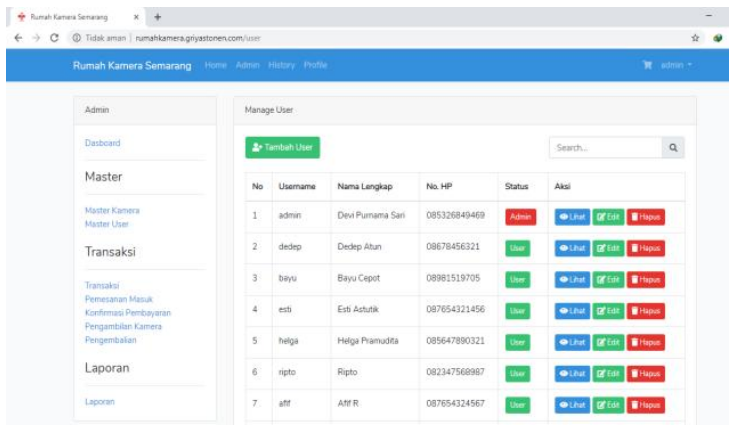

Gambar 11. Halaman Master User
Halaman ini berfungsi untuk menambahkan, mengedit, melihat detail data dan menghapus data user.

\section{KESIMPULAN}

Berdasarkan hasil pembahasan yang terdapat pada bab - bab sebelumnya, maka dapat ditarik kesimpulan sebagai berikut:

1. Sistem Informasi Penyewaan Kamera pada Rumah Kamera Semarang berhasil di bangun dengan menggunakan framework Laravel versi 5.7 yang mempunyai banyak fitur dalam mempermudah dan mempercepat proses pengkodean baik dari segi mesin atau dari segi tampilan user interface.

2. Sistem yang dibuat siap untuk diimplementasikan pada Rumah Kamera Semarang.

Berikut beberapa saran dan masukan untuk menunjang kesempurnaan sistem yang telah dikembangkan yaitu sistem perlu dilengkapi fasilitas chat online untuk memudahkan pelanggan menghubungi admin Rumah Kamera Semarang, dan sistem ini dapat dikembangkan untuk melakukan perpanjangan waktu sewa secara online.

\section{DAFTAR PUSTAKA}

Frayoga As., D.M., Fitriani, L., (2016), Jurnal Algoritma Sekolah Tinggi Teknologi Garut, Rancang Bangun Aplikasi Penyewaan Dan Pengelolaan Data Alat Kemping Berbasis Desktop Pada Perusahaan Perorangan $R z$ Adventure, Garut, Vol 13 No 1 2016, ISSN 23027339.

Kasman, A.D., (2015), Framework Laravel 5 Panduan Praktis dan Trik Jitu, CV. ASFA Solution, Cirebon.

Saputra, R., Widodo, A.W., Brata, A.H., (2018), Jurnal Pengembangan Teknologi Informasi dan Ilmu Komputer, Pengembangan Sistem Rental Kamera Online, Fakultas Ilmu Komputer Universitas Brawijaya, Vol 2 No 6 Juni 2018, ISSN 2548-964X.

Yudanto, A.L., Tolle, H., Brata, A.H., (2017), Jurnal Pengembangan Teknologi Informasi dan Ilmu Komputer, Rancang Bangun Aplikasi Sistem Informasi Manajemen Laboratorium . 